\title{
LOS PRECIOS DEL PAN EN MURCIA \\ EN EL SIGLO XVIII
}

CEFERINO CARO LOPEZ

\section{La dinámica secular}

Perfecta la concordancia entre las curvas de los precios del trigo y del pan '. No podía ser de otra manera: los dos asuntos están estrechamente rela. cionados, y subidas de precios y bruscas depresiones se repiten al mismo com. pás, excepto en contadas fechas.

La tónica general es una tendencia más acusada que la de los precios del trigo al acercarse al valor central de la serie durante el período 1680-1755, lo que significa que las oscilaciones del precio del pan son menos violentas en el sentido de que las diferencias entre mínimos y máximos arrojan saldos inferiores en sus valores a los correspondientes entre los cereales. Estamos, pues, ante lo que se puede considerar como un éxito del Pósito: haber evitado los grandes desequilibrios cíclicos o coyunturales de los productos de primera necesidad.

Pero el análisis del gráfico de los valores ponderados indica que este resultado se ha conseguido paliando dentro de lo posible la escasez de trigo con ofertas masivas de los graneros públicos y que nunca se ha prevenido una subida de los precios con los excedentes de los años anteriores. Lo contrario, esto es, que la coyuntura encontrara al Pósito desprevenido, ha ocurrido en varias ocasiones. Entre 1704 y 1707 los precios del grano experimentan un descenso de 25,1 a 23,5 reales por fanega, pero el pan sube de 0,48 a 0,7 maravedíes por onza, lo que atestigua de un fallo en la administración del público. Aunque no sean frecuentes, se pueden volver a encontrar otras ocasiones parecidas, como, de hecho, fue el caso entre 1714 y 1718 .

Difícil hablar de los movimientos cíclicos de los precios del pan por el efecto amortiguador realizado por la política de abastos: hablemos mejor de períodos de duración bastante irregular, empezando por años de precios muy

' Véase el estudio de Caro (1985), del que este trabajo es continuación. Allí se encontrarán indicadas la metodología seguida en la investigación, las fuentes del estudio y la bibliografía general. 
elevados. Entre 1677 y 1679 la onza de pan llegó a costar un 76,44 por 100 más que la media de los dos años anteriores; durante los quince años siguientes el precio medio fue inferior en un 60 por 100 al de este trienio, particularmente desdichado, dramático en verdad, como es fácil suponer.

Una fase de precios cuyas oscilaciones se localizan en la banda de los 40 69 maravedíes/onza dura desde 1681 hasta 1708 . La subida del año 1709 no se nota casi en los precios del pan: 0,7 maravedías/onza, por 0,6 en el año anterior y 0,51 en el siguiente. Perfecta en este caso la acción del Pósito, sobre todo teniendo en cuenta que se trata de una fase alcista de los precios del trigo. La acción de los administradores se ha llevado a término mediante la compra masiva de granos: el empleo de 1709 fue de 22,672 fanegas, con relación a las 17.410 del año anterior, mientras que en 1707 solamente se habían comprado 11.407: un crecimiento de los abastos que se cifra en un 56,62 por 100 en dos años, al que sigue otro entre 1708 y 1709 , cifrado en un 30 por 100 más en las cantidades de trigo acopiadas. Los regidores fueron previsores para atajar las consecuencias de la crisis - no sólo económica, sino también política- de 1709 . Este momento marca un cambio de la tendencia en los gráficos de los valores del pan. A partir de entonces, las fluctuaciones de los valores nominales y ponderados van haciéndose cada vez más violentas en ambas direcciones.

Años de bajos precios entre 1718 y 1720, 1724 y 1726, pero desde 1728 hasta el año de 1737 el precio no hace prácticamente sino subir. Faltan los datos de 1739 a $1741, y$, desde un valor bajo en 1742, la curva alcanza en 1750 una cifra superior en un 97,6 por 100 . En el último tercio del siglo xvilI no existen tendencias globalmentet definidas: entre 1769 y 1790 , tres alzas impresionantes; otras tantas depresiones con variaciones porcentuales que alcanzan valores de $-48,1$ por 100 en el bienio $1769-1770,+116$ por 100 entre 1781 y 1783 , para bajar en un 47,42 por 100 al año siguientte... Es lamentable no poder tener datos sobre las cosechas de la última parte del siglo, pero es evidente que la dinámica violenta de los precios del pan está anclada a los estrangulamientos de producción generalizados a finales del Dieciocho.

\section{Las crisis y los hombres}

La crisis del periodo 1677-1679 la viven los contemporáneos con plena conciencia de su gravedad. Ya en años anteriores habían sido prohibidas las sacas de granos a Valencia, pero ahora el Ayuntamiento, en marzo de 1677, debe recurrir al obispo para que venda su trigo al Pósito. El día 23 delega en una junta actividades y preocupaciones del abasto público, que se complica 
debido a «la muy corta cosecha» de ese año. Para agravar aún más la situación estalla la peste y, a primeros de junio, el Cabildo debe también pensar en preparar hospitales para recoger a los afectados ${ }^{2}$. El trigo en Lorca está carísimo por las muchas sacas que se han realizado; se encomienda al patrón del Almudí el empleo donde sea posible, y a duras penas se logra juntar 6.200 fanegas de Lorca, Totana y, en menor medida, del campo de la ciudad. De nuevo es preciso recurrir al obispo, en noviembre, y éste responde no disponer tampoco de nada de panizo. La libra de pan, que sólo pesa 13 onzas, se vende en 26 maravedíes. El día 4 de diciembre llegan a la ciudad $1.100 \mathrm{fa}$ negas de trigo mandadas desde Lorca por el obispo, pero ahora el pan cuesta 18 maravedíes por 12 onzas de peso. Los administradores se centran desesperadamente en la búsqueda de suministros en Totana, en Chinchilla, pero el trigo no se halla a menos de 5 ducados por fanega en marzo de 1678 . En abril es necesario reconocer públicamente que falta el grano, a la vez que los documentos oficiales atribuyen la responsabilidad a la Chancillería de Granada, que permitía las sacas de Lorca a pesar de la escasez que se estaba padeciendo. Además, la cosecha de ese año es limitada: ya son dos temporadas seguidas de baja producción, y en octubre es menester buscar trigo en Orán, a condición de que los precios - recomienda el Cabildo- no excedan los 8 reales de plata por fanega: la media de los precios pagados en los empleos anteriores había rondado los 35 reales de vellón.

La situación se hace dramática, como refleja la sesión del Ayuntamiento de 31 de octubre. Los panaderos no tienen trigo; la ciudad tampoco. No se puede repartir ni una fanega, y lo más grave no es que no lo haya en el Pósito, sino que no se encuentra en ninguna parte. A partir del día siguiente, dicen los regidores, no habrá pan. El 22 de noviembre se ajusta una partida de grano - providencial- desde Cartagena, procedente de Sicilia, pero es una gota en el mar de las necesidades de la ciudad. El pan, con 11 onzas de peso, cuesta ahora 22 maravedíes, y el año de 1679 sigue la misma tónica. La medida exacta del desastre la puede dar la afirmación formulada en la reunión del Cabildo de 9 de enero: "consta que en el Almudí no hay un grano de venta». En ese año pudo hacerse empleo de trigo procedente de Orán, pero ya muy tarde, en julio-agosto, y las casi 14.000 fanegas traídas desaparecen a los pocos días: en octubre de nuevo están los panaderos sin harina, y no puede extrañar que en esta situación hasta febrero de 1680 el pan no baje de 16 maravedíes por 12 onzas de peso. El Pósito no puede comprar, cuando consigue dar con una partida en Cartagena, más que $1.000 \mathrm{fa}$ negas, debido a la escasez de su presupuesto. El quebranto económico no deriva solamente de los esfuerzos de tres años sucesivos, sino también de la

\footnotetext{
' Cfr. Hernández Franco (1983).
} 
extraordinaria «escasez de moneda» de esos años de ajustes y maniobras monetarias en el Reino. En abril vuelve a faltar el pan; en el Pósito los granos sólo aseguran el consumo para veinte días, mientras que las necesidades de la población son apremiantes. Afortunadamente llega una buena cosecha y la pesadilla termina cuando el precio del pan alcanza los 10 maravedies por libra cabal, esto es, con su peso efectivo de 16 onzas, un valor tres veces inferior al de pocos meses. antes. Dejemos la palabra a los protagonistas para explicar cómo han podido ser

remediados todos estos reinos con gran cantidad de trigos que an llegado en diferentes naos a los puertos de Gibraltar Cádiz y Málaga y Almería y Alicante que dista doze leguas de aquí y todos los interesados en la venta del trigo tenían empleado en este género todos sus caudales con esperanza casi cierta de doblar tres veces sus empleos por la esterilidad del tiempo que se experimentava por el mes de noviembre y assido nuestro señor servido remediarla con su Divina providencia vajando los precios en la ciudad de Granada de cinquenta a quarenta y quatro, la de Lorca de treinta y dos a veinte $\mathrm{y}$ seis en el campo de Murcia que dista quatro leguas de esta ciudad desde treinta hasta veinte y seis y todos quantos tienen enzerrado el trigo y el panizo están rogando con estos géneros y no hallan compradores ${ }^{3}$.

La convulsión de 1708-1709 sigue la misma dinámica, pero en escala más reducida. En octubre de 1707 el Pósito empieza a repartir a los panaderos 500 fanegas de trigo a 23 reales cada una, cuando el año anterior había visto valores de 18,6 reales/fanega. Es el primer aviso de que la tormenta se aproxima: en febrero de 1708 se reparten ya 40 fanegas diarias a 24 reales; en abril se prohíbe la saca trigos; en mayo se habla abiertamente de que la cosecha peligra: se reparten diariamente 130 fanegas para suministro de las tahonas. En junio es posible comprar 1.400 fanegas en Lorca, pero esa cantidad es completamente inadecuada para las necesidades de la ciudad; el 18 de agosto la libra de pan, rebajada a 15 onzas de peso, y con precio de 8 maravedíes, pierde otra onza. En septiembre la esterilidad es general, y la libra sigue reduciéndose de peso, llegando a 13 onzas por el mismo precio. En veintidós días el pan ha subido en un 13,3 por 100. Entonces se manda hacer un registro de trigo en la ciudad, para comprobar los posibles acopios realizados por los particulares, mientras siguen las medidas reguladoras. El trigo pasa, entre el día 6 y el 16 de octubre, de 26 a 33 reales por fanega y el pan

${ }^{3}$ Archivo del Ayuntamiento de Murcia, Acuerdos Capitulares (en adelante, AA. CC.), 22-I-1684. 
cuesta ya 12 maravedies. Es preciso recurrir a los graneros eclesiásticos, que proporcionan 1.000 fanegas de panizo de Chinchilla, pero el invierno es durísimo. En enero siguiente se buscan mercaderes extranjeros que traigan trigo del mar, y a la vez la ciudad prohibe hacer pan blanco. La esperanza se enciende el día 4 de febrero, al contactar con un patrón de barcaza que ofrece trigo de Berbería por mediación de unos hombres de negocios de Cartagena, pero en condiciones leoninas: 3 pesos/fanega el precio, depósito o fianza de otros 3.000 y un seguro del 20 por 100 del valor. A pesar de lo oneroso, la ciudad aceptaría el trato, pero el día 6 todo se viene abajo por causas que no alcanzamos a conocer, y a partir de entonces la situación se mantiene «atribuiéndose a milagro la manutención hasta oy». Pero el milagro dura poco: el día 9 de marzo se avisa de que sólo queda trigo para tres días en el Almudi. Los administradores se han ido a buscarlo a Teruel, pero sólo dos semanas más tarde recibirán las primeras remesas al exorbitante precio de 62 reales/fanega. Nada más que una vez, durante los años terribles de 1678 y 1679, se había pagado por el trigo un precio semejante, y al asegurar el abasto en estas condiciones es preciso subir el precio del pan, esto es, bajar su peso. Ahora con 16 maravedíes se compran sólo 12 onzas de pan, y a pesar de lo prohibitivo de las condiciones tampoco queda asegurado el suministro; primero, el grano llega sin puntualidad y, luego, se agota. Otra vez, el 18 de abril, confiesan los regidores que «no queda trigo en la tierra más que para el día de mañana». El 29 llega el trigo de Aragón y se empieza a repartir a los panaderos inmediatamente. Se entregan 100 fanegas diarias para hacer un pan que se venderá al increíble precio de 20 maravedíes las 14 onzas. Tras la cosecha la baja del pan es sólo relativa: mismo precio para 16 onzas, pues se ha cogido bien poco, y en julio ya los panaderos se quejan de la escasez del género. No queda otra alternativa que la de buscar «un crédito en los vezinos cosecheros», que no parece dar resultado. En pleno mes de julio no hay panizo en el Pósito y es preciso pedirlo a las autoridades religiosas. Sin embargo, el verdadero alivio sólo llegará cuando se permite que las tercias reales se empleen en el abasto público. Vuelve a bajar el peso del pan: 13 onzas el día 3 de agosto, y 12 el 5 de octubre, siempre por el mismo precio. El 24 de ese mismo mes la ciudad decreta que los panaderos hagan panecillos especiales para los pobres al peso de 7 onzas y a poner en venta a 8 maravedíes. El precio real del pan es exactamente el mismo, pero influye el factor psicológico de poder disponer de una ración, aunque mínima, por 2 cuartillos. A partir de noviembre la onza de pan conservará su valor de 0,77 maravedíes hasta junio del año siguiente, y si el precio es elevado al menos es estable. El día 20 de junio por fin el Cabildo puede fijar el precio de la libra cabal en 8 maravedíes, o sea, un 23 por 100 más caro que el precio a que corría en 1706; pero la crisis se ha acabado. 
En esta segunda fase de crisis los precios del pan no llegaron a los niveles de los años 1677-1678, y una de las posibles explicaciones es que el empleo de trigo fue de 22.627 fanegas, de las cuales 4.500 compradas de Aragón y todas a un precio muy elevado. Si a pesar de estas inyecciones en el mercado de la ciudad -y a precio político- llegó a haber momentos de verdadera escasez, es fácil imaginar lo que hubiera podido suceder de no haber existido un Pósito de trigo:

Afortunadamente para la población, tras esta sacudida se dan varios años de buenas cosechas en 1710,1714, 1720, 1726 y 1727. Gracias a la de 1714 se llegó a vender el pan a 8 maravedíes por 18 onzas, 2 más del peso de la libra cabal, y en 1726 y 1727 a 6 maravedíes las 16 onzas. Los resultados de las malas cosechas de 1732 y 1733 hacen subir de pronto los precios, aunque sin alcanzar ni los valores ni las medidas extremas de las grandes crisis anteriores. Además, todos los indicios apuntan a una tendencia a la baja desde el año de 1734 hasta el de 1742 , que también experimentó buenas cosechas y en el que la libra de 14 onzas se vendía a 6 maravedíes. El trigo llega a las puertas del Almudí en abundancia y la ciudad se beneficia de una situación de precios no sólo bajos, sino también estables durante todo el año y hasta la cosecha del siguiente. Pero este período fue el último favorable desde el punto de vista de los precios. A partir de 1746 empieza una fase de cosechas «cortas» - cuatro consecutivas - que introducen una carestía endémica: los precios del trigo suben en los tres años en un 60 por 100, y los del pan en un 62 por 100. En agosto de 1748 la onza de pan cuesta 0,76 maravedíes y en febrero de 1749 se venden 14 onzas en 12 maravedíes; en abril, por el mismo precio, sólo se dan 13; en agosto, 12. Al año siguiente las cosechas son nulas por falta de lluvias, y lo que agrava la situación murciana, ya en el aspecto del abastecimiento, es la carestía «mayor que padecen los reinos de Andalucía y Mancha». La única esperanza de avituallamiento vuelve a ser el mar. En agosto el pan se vende a 10 maravedíes por 11 onzas. La ciudad se ve imposibilitada a paliar las necesidades de la población porque no se encuentran proveedores: en 1745 había comprado 15.955 fanegas para el Pósito, cantidad doblada al año siguiente en vista de las malas cosechas; pero cuando la escasez se generaliza es cada vez más difícil encontrar mercados de grano. Se compran 19.555 fanegas en 1748; menos en 1749, y en 1750 , precisamente cuando la crisis toca su punto más elevado, sólo se pueden traer a Murcia 9.520. Hasta junio de 1752 no se encontrará pan a un precio asequible o razonable. El año de 1755 será el último relativamente bueno en que el pan de tahona se vende a 8 maravedíes por 15 onzas. A partir de entonces, las crisis se generalizan: poca cosecha en 1757; crisis de abasto en 1765, cuando la libra de pan llamado francés llegó a costar, en octubre, 24 maravedíes por 15 onzas de peso; otra grave crisis de producción y abasto 
en 1769, en la que la administración ciudadana queda completamente desbordada y el precio del pan alcanza el valor más alto de todo el período estudiado... En 1773 hay otra carestía y otra grave crisis en 1785, año en que la onza de pan supera el valor de 1 maravedí, al vender en 12 la libra de 10 onzas. Vuelve la carestía en 1788-1789, y más acentuada en 1793, con los mismos precios que ocho años antes. El siglo se cierra con una nueva crisis - ¿o no sería más apropiado considerar todo el bloque temporal 17931798 como un solo gran momento de altísimos precios? - sin que la Administración pública pueda siquiera atreverse a solucionar los problemas de abastecimiento y de política de precios. Las tentativas de la Ilustración se han revelado ineficaces, y la libertad de tráfico y comercio de granos no está en condiciones de mejorar una situación estructural que los contemporáneos no consiguen dominar.

\section{El abasto}

Ninguna generación de murcianos entre 1675 y finales del Dieciocho se vio libre de las crisis de subsistencia - punto descollante de lo que fue, durante toda la edad preindustrial, endémica situación de precariedad en las condiciones de vida $-{ }^{4}$, y será interesante determinar los mecanismos y las fuentes de abastecimiento del Pósito de trigos.

El mecanismo es en sí poco complejo: llegando el momento de las cosechas, cuando la oferta va a ser mayor y los precios más bajos, en una reunión del Cabildo se encomienda al patrón y al administrador de la institución la compra de trigo para el abasto del año siguiente, operación llamada empleo. Los responsables del Almudí despachan entonces con sus agentes de confianza o reciben directamente ofertas de particulares, $\mathrm{y}$ a unos $\mathrm{y}$ a otros, una vez realizado el empleo de los granos, se les paga su comisión. Todos estos pormenores están perfectamente documentados en las cuentas que guardan los legajos del Pósito en el Archivo del Ayuntamiento de Murcia.

Las cuentas indican también las cantidades compradas en cada ejercicio y sus precios respectivos, así como los lugares de procedencia de los trigos. La comparación de los precios del trigo y los abastos permite afirmar que el factor precio no es casi nunca determinante en la cantidad adquirida, en el sentido de que a cosechas abundantes $-y$, por tanto, a bajos precios- deban corresponder compras masivas de granos. De hecho, esto ocurre sólo durante un período de menos de veinte años, entre 1682 y 1701 . Después los datos corren paralelos, lo que indica que la política de empleos se hace bajo las necesidades de la coyuntura: es necesario comprar mucho trigo principalmente

\footnotetext{
4 Como lo ha establecido Pérez Moreda (1980).
} 
porque la cosecha ha sido poca, y precisamente por ello los precios serán elevados. En época de bajos precios no merece la pena comprar porque la producción ha sido abundante y no se plantean problemas de abastecimiento. Indudablemente nos encontramos ante una situación y una mentalidad que son políticas, que no pueden buscar beneficio económico, sino que su eficacia se mide por la calidad de los servicios prestados. Todo ello resultará más patente aún si se comparan las cantidades de los empleos con los precios del trigo vendido para el Almudí. Sería de suponer que a mayor cantidad de trigo almacenado más bajo fuera su precio de venta, $y$, sin embargo, es exactamente al contrario cómo las cosas se desarrollan: los empleos son cuantiosos porque hay carestía y los precios suben precisamente porque no háy trigo en la ciudad, que es la razón por la que se han realizado importantes empleos. Entontes, ante esta necesidad, las compras de panizo han de ser realizadas forzosamente, aunque los precios sean altísimos, que es lo que normalmente ocurre. Teóricamente, ante este modelo de comportamiento económico la principal incógnita sería saber cuánto tiempo iban a poder durar los caudales del Pósito; pero, sin embargo, se trata de un falso problema, pues las curvas ponderadas de los precios del trigo comprado y vendido por el Almudí indican que las fluctuaciones de ambas variables son prácticamente iguales, o incluso, como ocurrió en 1708-1709, a favor de los precios de venta. La política de la administración ciudadana consiste, por tanto, en repercutir los precios de los empleos en el precio del pan: directamente, mediante el mecanismo de venta del panizo del Pósito a los panaderos; indirectamente, fijando los precios oficiales de la onza de pan.

Es así como se explica que en muy contadas ocasiones, a pesar de todo, faltara literalmente el pan; pero, en cambio, sus precios fueron siempre muy elevados -en tiempos de crisis, se entiende-. Cabe plantearse entonces si la política de abasto realizada por el Cabildo ha sido eficaz: sí, se puede responder, en relación con la cantidad, pero no, evidentemente, si se considera que varias capas de la población no podían acceder al pan debido no a que faltase, sino a su precio.

\section{La expansión de la demanda}

La dinámica violenta de la curva de los precios, tanto públicos -políticos- como de las cosechas, pone de manifiesto un crecimiento tendencial de los mismos a lo largo de todo el período estudiado. Determinar la causa de lo que es un fenómeno común en la economía del Antiguo Régimen no es globalmente posible; de tantas hipótesis puede adoptarse una, fácilmente demostrable, la del aumento del consumo. La población del siglo xvirl experimenta 
un auge incuestionable, $y$, si la productividad agrícola crece ${ }^{5}$, es evidente que la ley de la demanda y de la oferta tiene un papel considerable. El gráfico 1 recoge las cantidades de trigo compradas en los empleos del Pósito y sus fluctuaciones. Esta curva es la que muestra las oscilaciones más violentas, lo que no deja de ser desconcertante, pues el abasto es un servicio público que se realiza año tras año, y lo más lógico sería su estabilidad sobre la base de una cantidad media más o menos constante. Dos factores pueden haber influido en las variaciones: por un lado, los precios de los granos en el mercado, en relación con las necesidades de la población, y, por otro, la existencia de remanentes en los graneros públicos.

Confrontando los gráficos de las cantidades con el de los precios pagados, se notan movimientos no siempre coincidentes, aunque ya se ha visto que tampoco son incongruentes. Hay coincidencia en la subida de la curva hasta los años de 1680; paralelismo en 1693-1696, y, en general, se nota una dinámica orientada en la misma dirección entre los años 1727 y 1752 . Esto significa que en tales períodos creció el abastecimiento de granos del Pósito, a pesar de que los precios del trigo eran más elevados que en épocas anteriores, o tendencialmente a la alta, y de ello se ha dado ya una explicación. En estas ocasiones el Almudí actúa de mediador pasivo entre el mercado y el consumo, y se limita a paliar los efectos de la escasez-carestía de pan mediante la compra masiva de trigos, pero se trata de una intervención sobre la crisis, a posteriori, como puede observarse comparando este gráfico con el de los precios del pan.

Las crisis de los años $1675-1680,1685-1690,1695,1709-1712$, el período $1725-1740$, la crisis de los años $1748-1750$... El Pósito es, una vez más, indicador validísimo de la coyuntura económico-productiva, o, si se prefiere, la productividad en el sector agrícola determina la operatividad de este servicio.

Sin embargo, hay otros momentos en que el Almudí se adelanta a la coyuntura y realiza una política de prevención, esto es, cuando los empleos coinciden con precios de compra bajos o tendentes a la baja. Estos casos se dan en 1683-1687, con grandes compras, a la vez que el valor del trigo es reducido; se hace acopio de género en un momento de baratura. Lo mismo ocurre, probablemente, en 1704-1705, entre 1715 y 1719, cuando los empleos de trigo alcanzan una cuantía superior en un 53,45 por 100 a la media de los tres años anteriores, mientras que en la misma fase los precios bajan en un 15,2 por 100 ; en el año de 1725 se compran 12.000 fanegas de trigo; al siguiente, sólo 3.407 , y en $1727,20.000$, lo que representa un aumento en

s Una vez más hay que remitir a la obra básica sobre estos temas: Anes (1970), especialmente cap. VI, pp. 165 y ss. 
un solo año, sobre la suma de los dos anteriores, de un 25 por 100 . Por las mismas fechas, el precio del trigo de las cosechas pasa de 22 a 18,5 reales, y a 11,5 en 1727, precio mínimo del siglo. Naturalmente, el pan también ha bajado de 0,50 maravedí por onza a 0,36 en 1727; luego el trigo no se está comprando para hacer frente a necesidades actuales, sino que se aprovecha su abundancia para prevenir el futuro.

\section{Las fuentes del suministro}

El principal mercado donde la ciudad se surtía fue tradicionalmente Lorca, no sólo como lugar de producción, sino también en cuanto etapa de recepción de los granos importados de Andalucía al Reino de Murcia. En cualquier caso, el trigo de la «ciudad de Lorca y sus términos donde de hordinario se acostumbra hacer el empleo del Pósito" ${ }^{6}$, como dicen los regidores, es sinónimo de pan en Murcia.

En efecto, el 39,69 por 100 de todo el trigo comprado por el Almudí procede de Lorca ${ }^{7}$. Debe ser por eso que Espinalt decía que «si llueve a tiempo es prodigiosa su cosechaw ${ }^{8}$. Considerando el peso específico de las compras en esta villa durante varios lustros, se puede apreciar, sin embargo, que Lorca no es, ni mucho menos, un punto obligado del abasto: entre 1689. 1690 su aportación à los empleos del Pósito representó el 70,75 por 100 del total, pero en 1736-1740 sólo fue el 3,79 por 100, y en 1751-1755 el 1,15 por 100. En cambio, en estos momentos crece vertiginosamente la compra del trigo de mar, traído de Cartagena, Alicante y, en una ocasión, de Valencia. El trigo de mar representa globalmente el 21,6 por 100 de los totales documentados de los empleos, pero su presencia se concentra siempre en momentos cruciales, como son los intervalos de 1751 a 1755, cuando Cartagena aporta el 38,93 por 100 de todo el panizo del Almudí; en 1731-1735 y 1736-1740, Alicante vende, primero, el 30,49 por $100 \mathrm{y}$, después, el 48,28 por 100 del grano para Murcia. En la crisis de 1676-1680, Cartagena contribuyó en los empleos con el 40,47 por 100, y Valencia con un 11,66 por 100 del total, por lo que más de la mitad del trigo consumido en aquellos años fue de mar.

La relación entre los tres puertos de mar hacia los que Murcia, naturalmente, gravita se decanta en favor de Alicante desde principios del siglo xvmr.

- AA. CC., 13-VIII-1694.

7 En este caso no tendría mucho sentido trabajar con números absolutos porque las series no son continuas y faltan datos para varios años. Los porcentajes indicados se refieren al total de años para los que se han encontrado indicaciones en el Archivo del Ayuntamiento de Murcia.

- Esta y la cita siguiente están tomadas de Espinalt (1778). 
Hasta 1680 , Cartagena ha proporcionado el 23,73 por 100 de todo el trigo del Pósito, y Alicante solamente el 7,37 por 100. El caso de Valencia es episódico, centrado como está en una intervención particular y de acuciante necesidad en la crisis de 1676-1680. Después de entonces, Murcia no volverá a realizar operaciones masivas en la ciudad del Turia. Lo más significativo es que durante la crisis de 1708-1709 no se importa trigo de mar; se llega incluso a traer 4.500 fanegas de Aragón, pero no se puede recurrir ni a Alicante ni a Cartagena, y parece que es entonces cuando este puerto empieza a ser desplazado por aquél. En 1730 llegan 3.000 fanegas de trigo de Alicante, que pasan a más de 19.000 en el quinquenio $1731-1735$, y a 30.000 en el mismo período sucesivo. Solamente en el año de 1750 , Cartagena vende a la ciudad 9.155 fanegas de trigo de Sicilia y Cerdeña, y en 1765 otras 5.700 fanegas más. Pero ya no quedan más datos para cuantificar las aportaciones de trigo ultramarino de esta fecha en adelante. Globalmente, Cartagena aporta el 7,58 por 100 de las cantidades traídas al Almudí, principalmente en el siglo xvir, mientras que Alicante proporciona el 12,99 por 100 , casi todo en el Dieciocho. Estos datos, sin embargo, sólo son significativos referidos a la primera mitad de la centuria por falta de documentación sobre los empleos posteriores. Cabe la posibilidad de que, encontrando los registros de cuentas de la segunda mitad del siglo, se pudiera hablar de una nueva importancia del trigo de mar, debido a las graves oscilaciones con que acaba el siglo, y también sería posible cuantificar con mayor exactitud el largo período; pero, por el momento, no hemos conseguido dar con más datos concretos.

Lo que es indudable es que la ciudad se vuelve principalmente hacia la tierra firme en busca de subsistencia; Lorca primero, aunque no todo el trigo allí comprado fuera cosecha autóctona ${ }^{9}$. Los otros grandes mercados de abastecimiento son Andalucía y, sobre todo, La Mancha, incluyendo en esta denominación geográfica a Albacete y Chinchilla. De esta villa el Atlante Español dice que es tal su abundancia «que sus tercias ascienden todos los años a veinte y cinco mil fanegas de todos los granos». Globalmente, La Mancha proporciona el 20,13 por 100 del trigo importado, y Andalucía el 5,96 por 100. Las aportaciones de esta zona, sin ser episódicas, han tenido mayor relieve en dos momentos concretos: $1706-1710$, cuando representan el 60,64 por 100 del total de los empleos, y en $1716-1720$, sumando el 49,87 por 100 . En este lustro todo el trigo del Pósito se compró prácticamente en Lorca y Andalucía, pero a partir de los años cuarenta del siglo xviII esta fuente de suministros pierde

- A pesar del panegirico de Morote sobre el trigo: «las cosechas de éste en los términos de esta ciudad son regularmente grandes aunque comúnmente las tienen por medianas cosechas; pues no se reputan por abundantes a las que no dan quarenta o cinquenta por una fanega, o setenta o más las de trigo, como en los años de diez, catorce y diez y siete, de el siglo que correw. Morote (1741), p. 264. 
importancia, a la vez que La Mancha se va perfilando como granero de Murcia. En 1751-1755 es el trigo manchego, en una proporción del 59,61 por 100 del total, el que salva la crisis, junto con Cartagena, que llega a incidir en un 38,83 por 100 en los empleos. Entre los años de 1725 y 1740 representa constantemente un promedio superior al 30 por 100 del adquirido para el Pósito.

Es clarísima la permanencia de las estructuras económicas y de los recursos agrícolas en la larga duración: merece la pena traer a la memoria las palabras de Chacón Jiménez, quien, hablando del siglo xvi, traza un cuadro perfectamente coincidente con el de los dos siglos sucesivos. En casos de necesidad,

primeramente se pide ayuda a las villas y lugares del reino; Totana, Lorca, Cartagena, Mula, Jumilla, Yecla, Yeste, Alhama, Albacete, Chinchilla, pero cuando la situación es grave el problema suele afectar a todo el reino y, por lo tanto, los graneros de estas villas están tan vacíos como los de Murcia;

y entonces hay que recurrir a la producción cerealícola de La Mancha, siguiendo -en sentido inverso- la vía de exportación de la seda ${ }^{10}$.

Los demás lugares representan una aportación tan poco significativa que apenas inciden en el abastecimiento de la capital. Solamente el campo y huerta de Murcia aportan en conjunto el 6,97 por 100 de lo necesario para el avituallamiento del Pósito, y ello en años contados. En 1771-1775, el 46,30 por 100 del trigo era del campo de Murcia, pero en los demás momentos a duras penas alcanza un 20 por 100 -de 1681 a 1685 -, y superar el 10 por 100 de las cantidades totales aparece como un logro que sólo se consiguió tres años.

En su conjunto, se trata de una situación muy distinta de la de otra ciudad mediterránea, Valencia, según los datos de Pérez Aparicio". El trigo viene a la ciudad del Segura, sobre todo, de Lorca y de La Mancha, y juntas representan estas importaciones casi el 60 por 100 del conjunto de todo el período estudiado; el trigo de mar apenas si es una quinta parte de los suministros, y la porción restante se consigue en el propio campo - limitadísimamentey en zonas intermedias entre Andalucía y La Mancha, como límites extremos, y el centro de consumo; Totana, Yecla, Jumilla y Orihuela proporcionan parte de sus escasos recursos para paliar las necesidades del centro administrativo y económico del Reino, que adquiere, por otras razones y por ésta, en relación con su entorno geográfico, el carácter de dominación parasitaria.

\footnotetext{
10 Chacón Jiménez (1978), pp. 15-16.

1 Pérez Aparicio (1975), p. 306.
} 


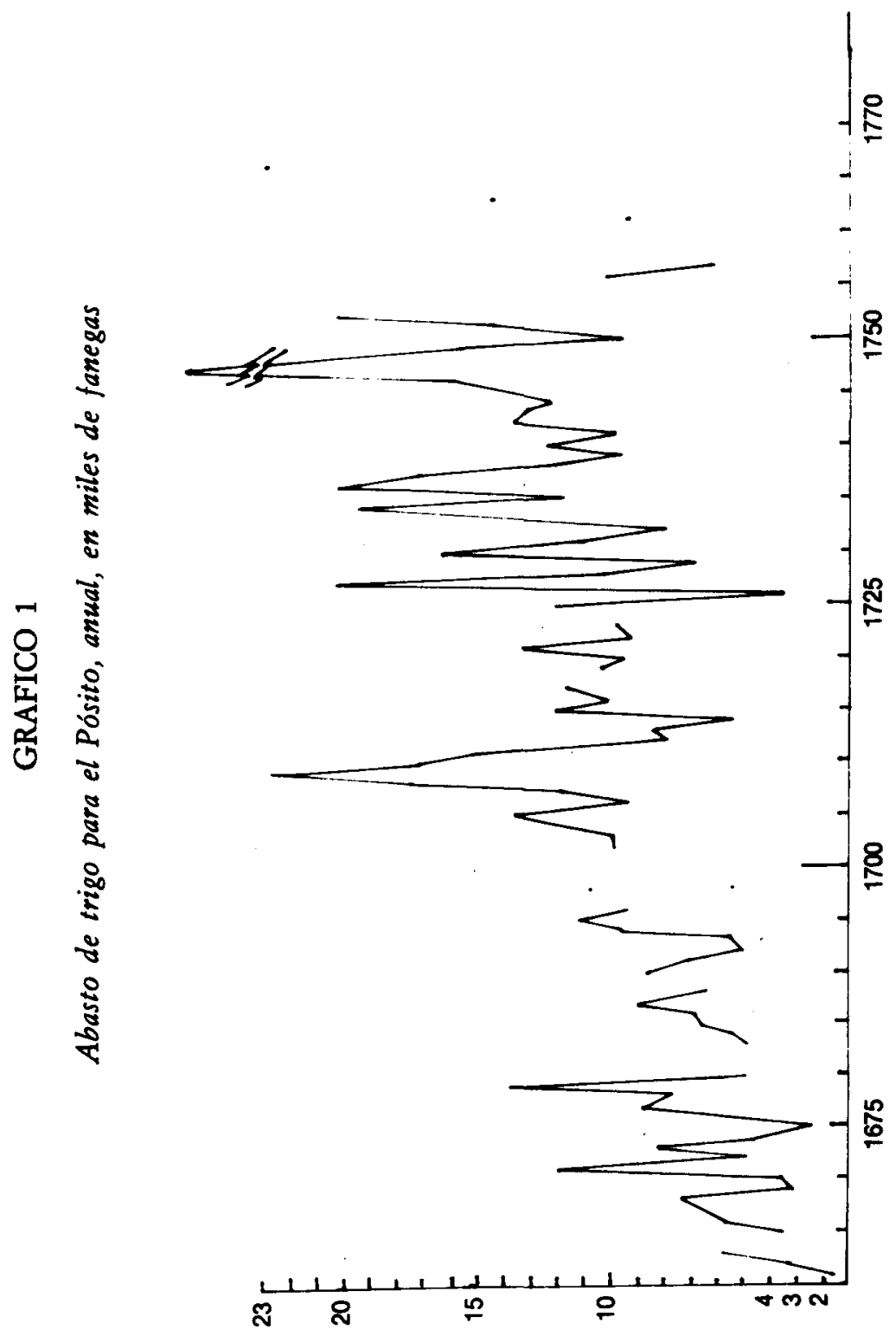




\section{CUADRO I}

Precios medios anuales de la onza de pan en Murcia. Años agrícolas, de 1 de agosto a 31 de julio. En reales de vellón

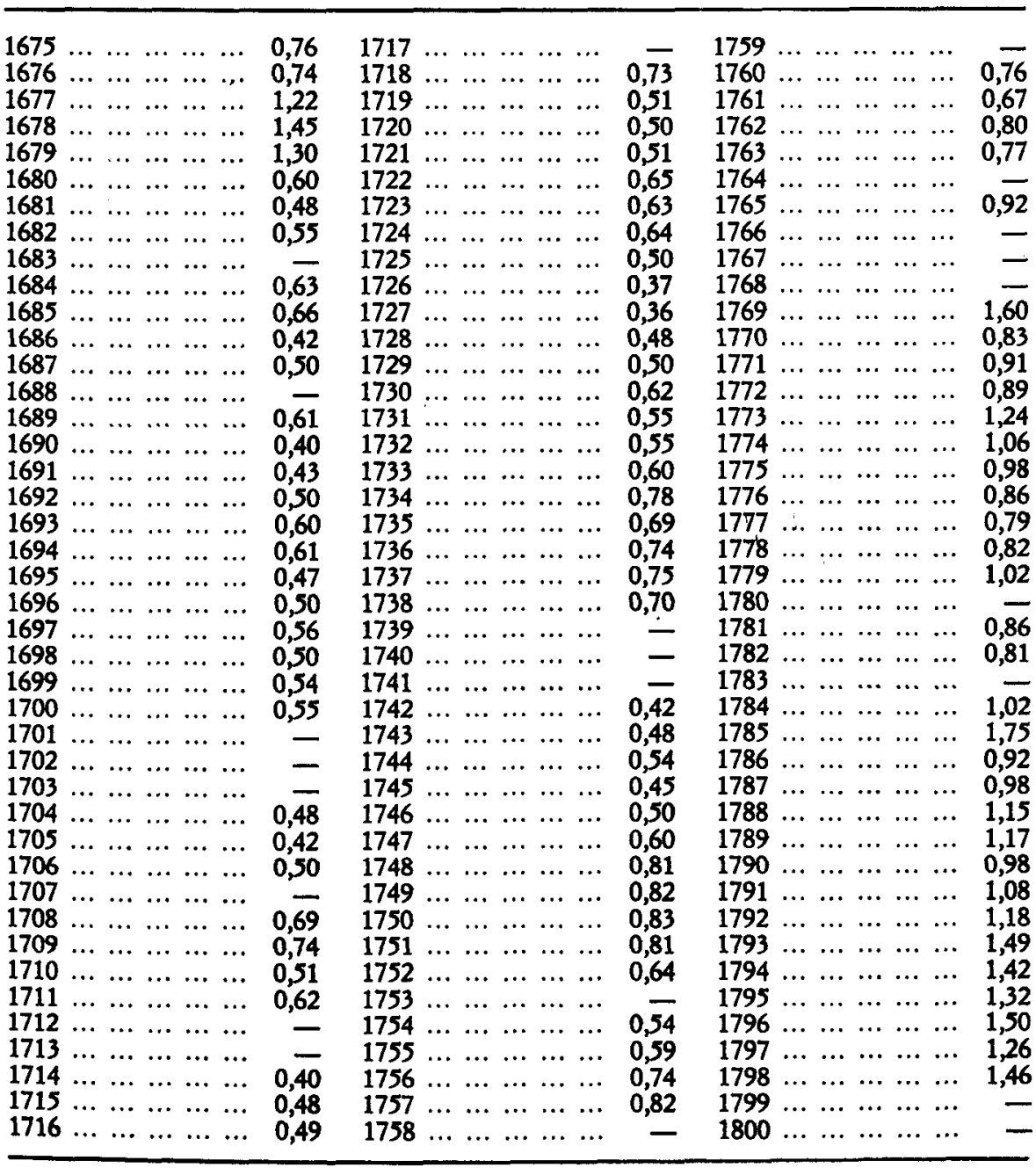




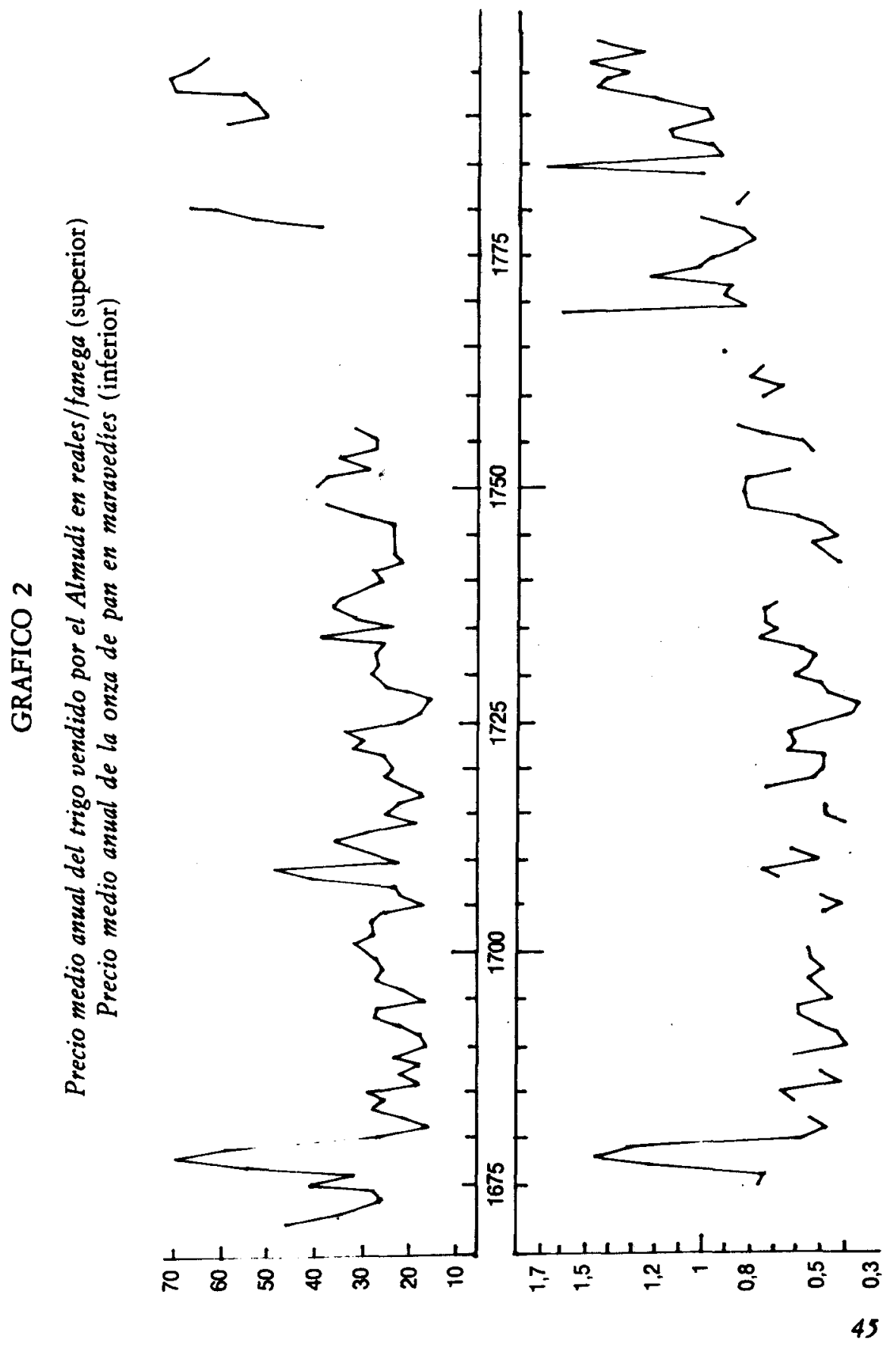




\section{CUADRO II}

Valores ponderados de los precios medios del trigo de los «empleos».

En reales de vellón. Por quinquenio, base $1726-1750=100$

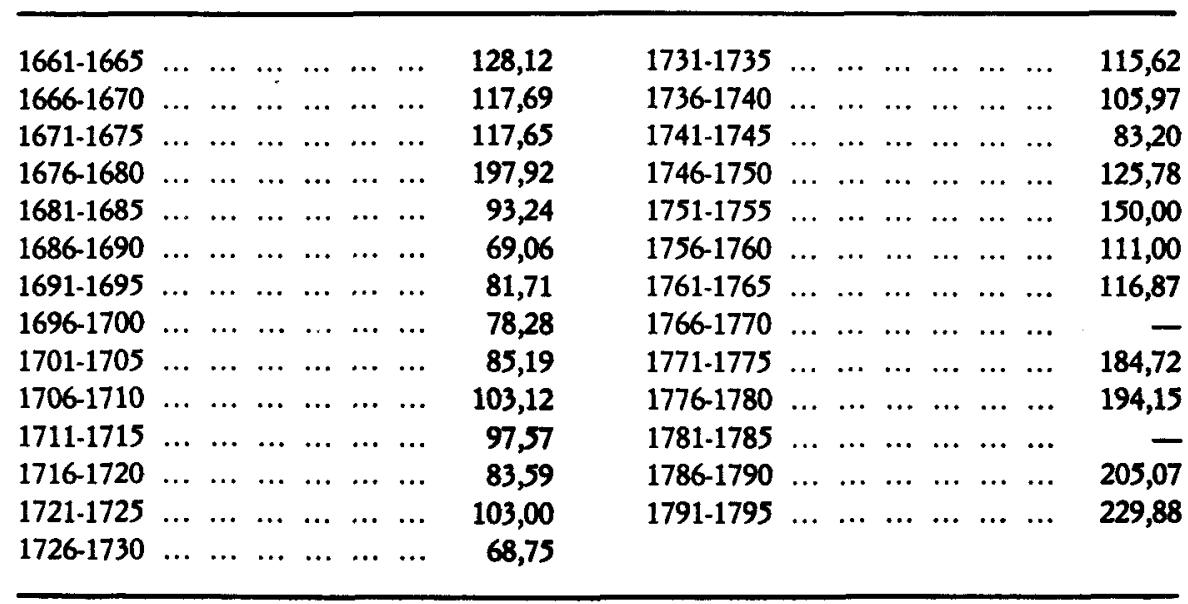




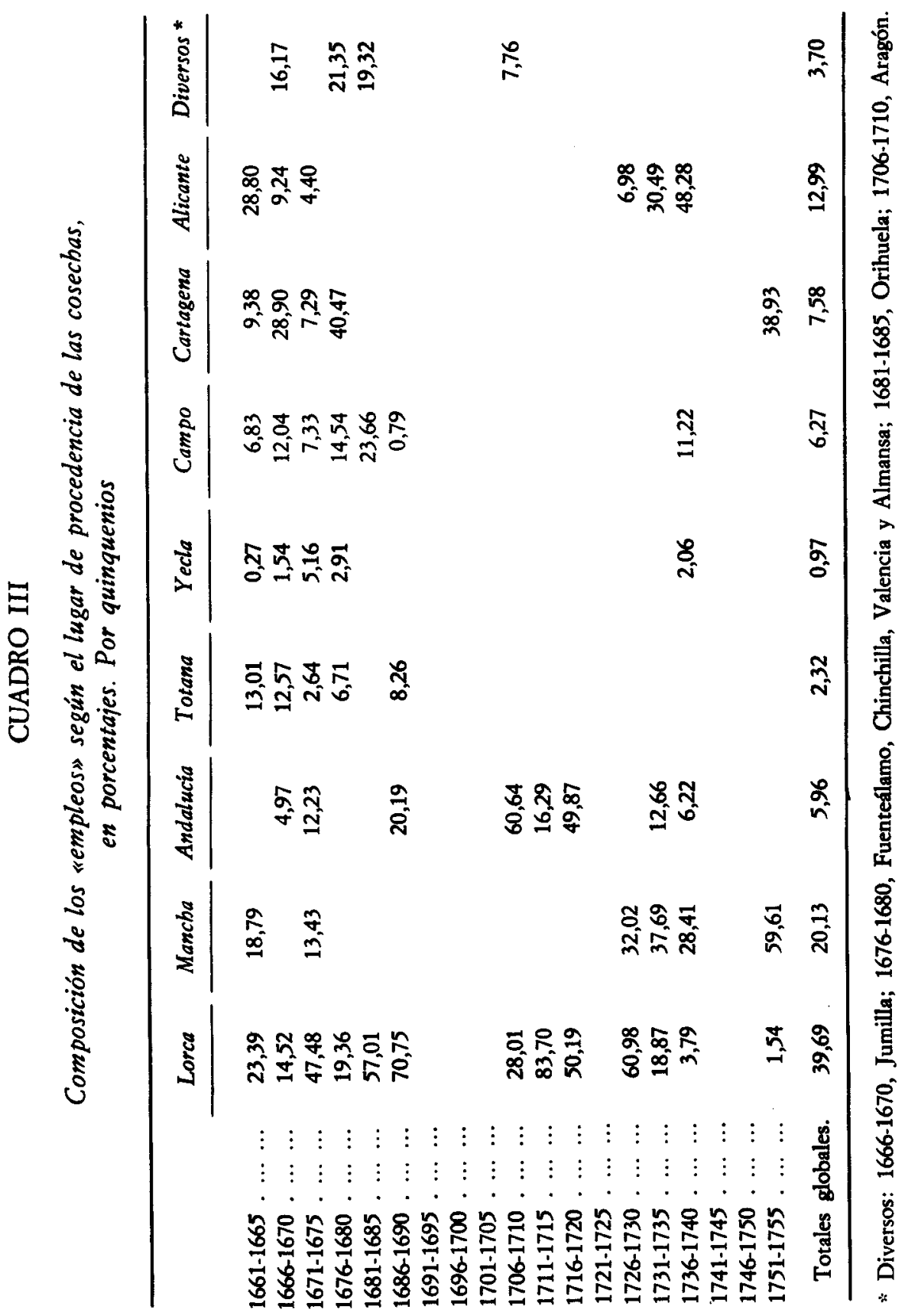




\section{CUADRO IV}

Cuantia de los «empleos» del Pósito. En fanegas de trigo, por quinquenio

\begin{tabular}{lllllllllllllllll}
$1661-1665$ & $\ldots$ & $\ldots$ & $\ldots$ & $\ldots$ & $\ldots$ & $\ldots$ & 17.023 & $1711-1715$ & $\ldots$ & $\ldots$ & $\ldots$ & $\ldots$ & $\ldots$ & $\ldots$ & 48.657 \\
$1666-1670$ & $\ldots$ & $\ldots$ & $\ldots$ & $\ldots$ & $\ldots$ & $\ldots$ & 18.549 & $1716-1720$ & $\ldots$ & $\ldots$ & $\ldots$ & $\ldots$ & $\ldots$ & $\ldots$ & 43.197 \\
$1671-1675$ & $\ldots$ & $\ldots$ & $\ldots$ & $\ldots$ & $\ldots$ & $\ldots$ & 32.700 & $1721-1725$ & $\ldots$ & $\ldots$ & $\ldots$ & $\ldots$ & $\ldots$ & $\ldots$ & incom. \\
$1676-1680$ & $\ldots$ & $\ldots$ & $\ldots$ & $\ldots$ & $\ldots$ & $\ldots$ & 40.950 & $1726-1730$ & $\ldots$ & $\ldots$ & $\ldots$ & $\ldots$ & $\ldots$ & $\ldots$ & 42.924 \\
$1681-1685$ & $\ldots$ & $\ldots$ & $\ldots$ & $\ldots$ & $\ldots$ & $\ldots$ & 12.448 & $1731-1735$ & $\ldots$ & $\ldots$ & $\ldots$ & $\ldots$ & $\ldots$ & $\ldots$ & 62.407 \\
$1686-1690$ & $\ldots$ & $\ldots$ & $\ldots$ & $\ldots$ & $\ldots$ & $\ldots$ & 31.352 & $1736-1740$ & $\ldots$ & $\ldots$ & $\ldots$ & $\ldots$ & $\ldots$ & $\ldots$ & 62.200 \\
$1691-1695$ & $\ldots$ & $\ldots$ & $\ldots$ & $\ldots$ & $\ldots$ & $\ldots$ & incom. & $1741-1745$ & $\ldots$ & $\ldots$ & $\ldots$ & $\ldots$ & $\ldots$ & $\ldots$ & incom. \\
$1696-1700$ & $\ldots$ & $\ldots$ & $\ldots$ & $\ldots$ & $\ldots$ & $\ldots$ & incom. & $1746-1750$ & $\ldots$ & $\ldots$ & $\ldots$ & $\ldots$ & $\ldots$ & $\ldots$ & incom. \\
$1701-1705$ & $\ldots$ & $\ldots$ & $\ldots$ & $\ldots$ & $\ldots$ & $\ldots$ & incom. & $1751-1755$ & $\ldots$ & $\ldots$ & $\ldots$ & $\ldots$ & $\ldots$ & $\ldots$ & 23.575 \\
$1706-1710$ & $\ldots$ & $\ldots$ & $\ldots$ & $\ldots$ & $\ldots$ & $\ldots$ & 57.918 & & & & & & & & & \\
\hline
\end{tabular}

\section{BIBLIOGRAFIA}

ANes, G. (1968): «Los pósitos en la España del siglo xvirm», en Moneda y Crédito, 105. - (1970): Las crisis agrarias en la España moderna, Madrid.

Anes, G., y Le Flem, J. P. (1965): «La crisis del siglo xvir», en Moneda y Crédito, 93.

CARo LOPEZ, C. (1985): «Las oscilaciones del precio del trigo en una ciudad del Levante: el caso de Murcia, 1675-1800*, en Revista de Historia Económica, 2.

Ch ACón Jiménez, F. (1978): «Caminos, hombres y trigo», en Anales de la Universidad de Murcia.

Espinalt, B. (1778): Atlante Español, Madrid.

Giménez López, E. (1981): Alicante en el siglo XVIII, Alicante.

Grupo 75 (1977): La economía del Antiguo Régimen, Madrid.

Hamilton, E. J. (1969): War and prices in Spain 1651-1800, Nueva York.

Hernández Franco, J. (1981): «El precio del trigo y de la carne en Lorca», en Murgetana, 1.

- (1983): «Morfología de la peste de 1677-1678», en Estudis, 9.

Lemeunier, G. (1983): «La coyuntura murciana: población y producción en el Siglo de Orow, en Cuadernos de Historia, 10.

Morote, P. (1741): Antigüedades y blasones de la ciudad de Lorca, Murcia.

Palop Ramos, J. M. (1976): El litoral valenciano y el avituallamiento de Madrid, Valencia.

- (1977): Fluctuaciones de precios y abastecimiento en la Valencia del siglo XVIII, Valencia.

Pérez Aparicio, C. (1975): «El trigo y el pan en Valencia, 1700-1713*, en Cuadernos de Historia, 5.

Pérez MoredA, V. (1980): Las crisis de mortalidad en la España interior, Madrid. 